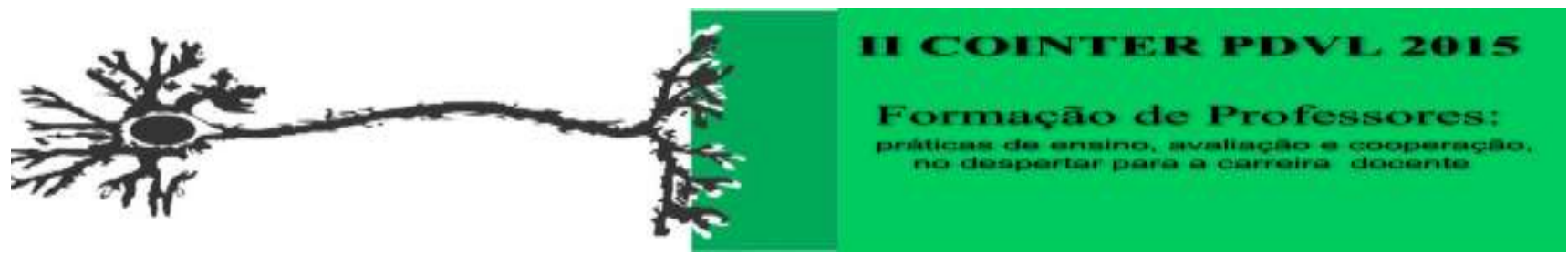

\title{
AULAS DE CAMPO PROMOVIDAS PELO PIBID DE GOOGRAFIA DO IFRN CAMPUS NATAL CENTRAL NA ESCOLA ESTADUAL PROFESSOR FRANCISCO IVO CAVALCANTI
}

\author{
Apresentação: Pôster \\ João Batista dos Santos ${ }^{1}$; André Elias de Oliveira Nóbrega ${ }^{2}$; Maria de Lourdes Penha Santos \\ ${ }^{3}$; Jorge Magno da Costa ${ }^{4}$
}

\section{Introdução}

Pensando em dispor aos alunos novos meios de se compreender a Geografia, o PIBID de geografia do IFRN campus Natal Central atuante na escola estadual Francisco Ivo Cavalcanti, localizada no bairro de Dix Sept Rosado, Natal-RN, executou ao longo de sua atuação na referida escola aulas de campos como forma de dinamizar o estudo dos conceitos geográficos e proporcionar aos alunos novas leituras das paisagens e vivencias geográficas.

Este relato se propõe a fazer a memória das aulas de campos realizadas pelo PIBID na escola Francisco Ivo Cavalcanti.

\section{Fundamentação Teórica}

A aula de campo é, grosso modo, a ferramenta pedagógica pelo qual os alunos tem a oportunidade de vivenciar a realidade dos conceitos estudados em sala de aula em que a leitura da paisagem possibilita a capacidade do aluno sintetizar conceitos, aguçar a observação, descobrir novas paisagens e conhecer lugares nunca antes visitados por eles.

É uma prática relevante para a compreensão e leitura do espaço geográfico pois a aula de campo possibilita aos alunos a integração dos processos da natureza e a percepção deste processos como um todo e não isoladamente.

Segundo os Parâmetros Curriculares (1998, p. 19):

O lugar deixou de ser simplesmente o espaço em que ocorrem interações entre o homem e a natureza para incorporar as representações simbólicas que constroem juntamente com a materialidade dos lugares, e com as quais também interagem.

Assim, a interação dos estudantes com os lugares é de essencial condição para uma boa aprendizagem, o que pode ser obtido eficazmente com a realização de aulas de campo, pois a

\footnotetext{
${ }^{1}$ Aluno de geografia, IFRN, e-mail: joaoseneca@yahoo.com.br

${ }^{2}$ Aluno de geografia, IFRN, E-mail: andre_009@hotmail.com

${ }^{3}$ Aluna de geografia, IFRN, E-mail: lourdespenha1@hotmail.com

${ }^{4}$ Professor de geografia, UFRN, E-mail:
} 
percepção espacial poderá ser mais bem apreendida quando os estudantes podem ter contato com a paisagem in loco, na qual, conforme os Parâmetros (1998, p.23).

Uma paisagem, seja de uma rua, de um bairro, ou de uma cidade, além de representar uma dimensão concreta e material do mundo, está impregnada de significados que nascem da percepção que se tem dela. No seu cotidiano os alunos convivem de forma imediata com essas representações e significados que são construídos no imaginário social.

Portanto, visualizar, analisar, interpretar e contemplar a paisagem faz parte do aprendizado e estará sendo mais bem apreendido se os estudantes tiverem um contato mais intimo com o meio.

\section{Metodologia}

O trabalho ora exposto é um relato de experiência fruto das atividades realizadas pelo PIBID de geografia do IFRN campus Natal Central na escola estadual Francisco Ivo Cavalcanti em NatalRN entre 2012 e 2014. teve como referencia metodológica os relatórios compostos pelos alunos feitos após as aulas de campo.

\section{Resultados e Discussões}

A primeira aula de campo foi realizada na cidade de Serra Caiada-RN, localizada na região Agreste do Rio Grande do Norte, teve por objetivo trabalhar com as temáticas de Geologia e Astronomia, onde foram observados os aspectos físicos como a estrutura geológica e a formação da paisagem e a observação astronômica.

Serra Caiada foi escolhida para a aula de campo pela sua importância, posto que lá está a rocha mais antiga da América Latina e que dá nome ao municipio, com cerca de 3,4 bilhões de anos. Outro aspecto importante à escolha do local deve-se ao seu nível de poluição atmosférico reduzido, tornando-o assim um local propício à observação astronômica, o que contribuiu para o entendimento dos estudantes e ao mesmo tempo possibilitando despertar um interesse maior pelo estudo da Astronomia. Procurou-se perceber identificar as principais constelações estrelar e revisar conceitos trabalhados em sala como, movimentos de rotação e translação, solstícios e equinócios, eclipse.

A aula de campo ocorreu entre 26 e 27/102012, e estiveram presentes 40 participantes, sendo 6 professores, 7 bolsistas do IFRN, 1 motorista e 26 estudantes.

De forma especifica esperou-se a compreensão do conceito de paisagem, dos aspectos socioespaciais na construção de um município; a percepção da Geografia como ciência que contribui na compreensão do espaço e da Astronomia como ciência importante para aspectos 
geográficos como as estações, clima e outros fenômenos. Esta aula de campo foi realizada em parceria com o PIBID de Física da mesma instituição de ensino.

A segunda aula de campo do PIBID/FIC teve como destino os municípios de Taipu e Poço Branco, ambos localizados na Mesorregião Leste Potiguar, na microrregião Litoral Nordeste do Rio Grande do Norte, também conhecida como território do Mato Grande realizada no dia 17 de agosto de 2013.

Teve como objetivo estudar os municípios de Taipu e Poço Branco abrangendo seus aspectos físicos, geográficos e culturais, visualizar os componentes da paisagem local para descrever suas variadas formas e composição; estudar as atividades industriais que fazem parte da economia local, como a criação de búfalos, na Tapuio Agroindustrial S\A; visitar a Barragem de Poço Branco entender os componentes da paisagem modificadas pela construção da mesma e estudar o aspecto urbano da primeira cidade planejada do Rio Grande do Norte.

Nesta aula de campo esteve presente 35 participantes dentre estes 3 professores, 6 bolsistas do PIBID, 1 motorista e 28 alunos

O Rio Grande do Norte possui cerca de $70 \%$ de seu território constituído de pequenas cidades de até 12 mil habitantes conforme Silva (2009), estudar dois que se inclui nesse percentual foi uma oportunidade única para os alunos que moram na maior cidade do estado, ou seja, a capital potiguar, Natal.

A justificativa para a escolha dos dois municípios visitados esteve nas peculiaridades existentes nos mesmo. No caso de Taipu é o único município de estado que tem na sua cadeia produtiva a criação de búfalos em que a produção derivada destes é destinada para toda região do nordeste e do próprio estado do Rio Grande do Norte, esta produção está na empresa Agrodustrial Tapuio S/A distante $12 \mathrm{~km}$ da sede, nesta cidade também foi estudado o centro histórico da cidade, pois se trata de uma cidade do final do século XIX onde se tinha em seu sitio histórico muitos prédios do final do século XIX e inicio do século XX.

No tocante a Poço Branco neste município se encontra a barragem engenheiro Jose Batista do Rego construída entre 1958 e 1969 para represar o rio Ceará-Mirim, Poço Branco é também a primeira cidade planejada do Rio Grande do Norte.

A terceira aula de campo do PIBID/FIC na data de 18/11/2014 entre as cidades de Natal, Nísia Floresta e Nova Cruz. Teve como objetivo conhecer e estudar os municípios que foram beneficiados pela estrada de ferro Natal-Nova Cruz, conhecer o processo de implantação do sistema de transporte ferroviário no estado do Rio Grande do Norte e sua importância para o desenvolvimento econômico do estado; reconhecer a importância histórica das estações ferroviárias 
construídas no final do século XIX no RN e estudar as características do modal de transporte ferroviário sua implantação e decadência

\section{Figura 1.Turma da aula de campo na estações ferroviárias da Ribeira (a esquerda) e da Rocas em Natal-RN}
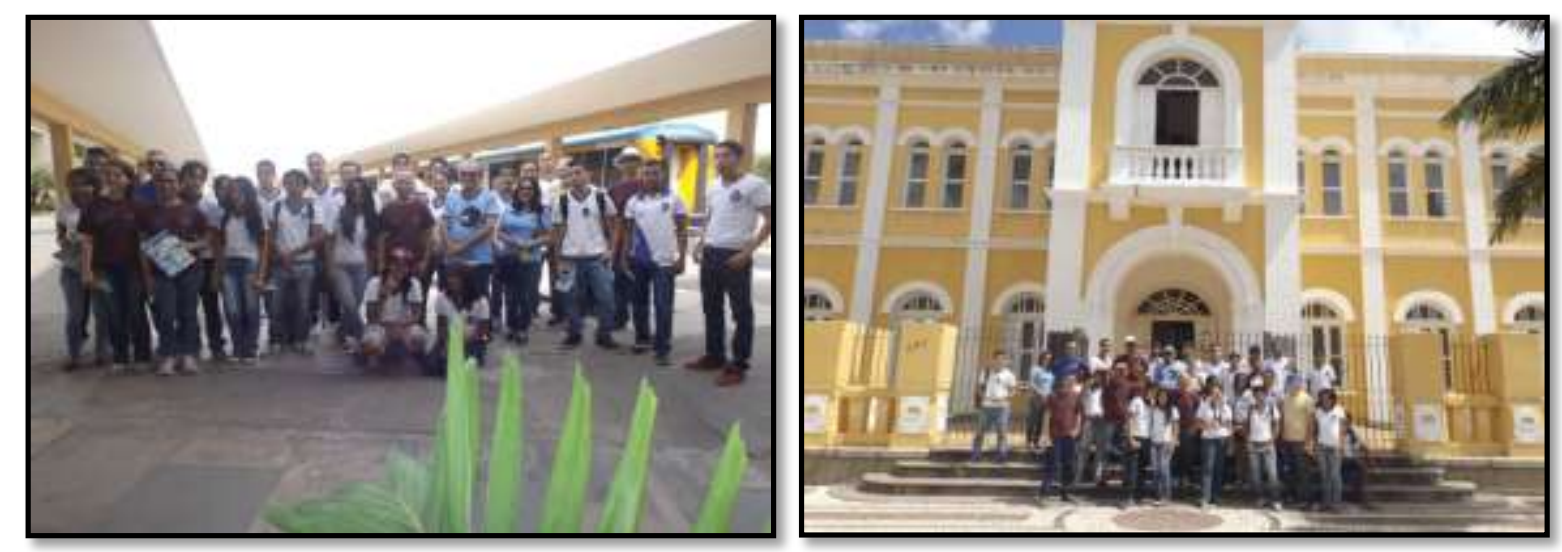

Fonte: João Batista dos Santos, 2014.

O percurso foi realizado indo inicialmente para a estação central da CBTU na Ribeira, a primeira a ser construída no RN em 1881, logo em seguida foi visitada a antiga estação da EFCRN nas Rocas, inaugurada em 1906 depois a estação de Nísia Floresta (antiga Papari) e por fim a estação de Nova Cruz, esta inaugurada em 1883, aquela em 1881.

$\mathrm{Na}$ estação da Ribeira técnicos da CBTU demonstraram a situação atual do transporte ferroviário do RN e a importância histórica da estação da Ribeira, atualmente é a estação central e sede da superintendência da CBTU; na estação das Rocas, foi estudado as características arquitetônicas da estação inaugurada em 1906 e sua importância na história da cidade de Natal e no transporte ferroviário do estado sendo o prédio tombado pelo IPHAN, as estações de Nísia Floresta e Nova Cruz também tem suas respectivas peculiaridades. tendo sido inaugurada em 1881 é uma estação de arquitetura neoclássica tombada como patrimônio histórico do RN. A estação de Nova Cruz foi inaugurada em 1883 sendo o ele entre o estado do Rio Grande do Norte e os estados vizinhos do nordeste, tem uma arquitetura peculiar em dois pavimentos, atualmente sedia a casa de cultura daquela cidade.

A atividade procurou despertar nos alunos o conhecimento do transporte ferroviário bem como a importância histórica e geográfica das estações ferroviárias dada as suas peculiaridades e formas arquitetônicas. 


\section{Considerações finais}

O objetivo das aulas campo promovida pelo PIBID de geografia do IFRN do campus Natal Central na escola estadual professor Francisco Ivo Cavalcanti foi proporcionar aos alunos uma vivência real dos temas abordados em sala de aulas relativos aos conteúdos apreendidos teoricamente. Além de proporcionar aos alunos a vivencia da realidade, a leitura critica da paisagem, as transformações espaciais e as peculiaridades dos lugares as aulas de campo proporcionaram também uma vivencia social importante que contribuíram para a formação humana dos alunos.

Para os professores foi um momento de dinamizar suas práticas educativas e quanto aos bolsistas do PIBID as aulas de campo possibilitaram um aprofundamento da convicção da escolha da Geografia como meio de atuação no magistério.

\section{Referências}

BRASIL. Secretaria de Educação Fundamental. Parâmetros curriculares nacionais: geografia. Secretaria de Educação Fundamental. Brasília: MEC/SEF, 1998.

CBTU. http://www.cbtu.gov.br

IBGE. http://www.ibge.gov.br

MORAIS, Marcus Cesar Cavalcanti de. Terras Potiguares. $3^{\text {a }}$ ed. Natal-RN, Ed. Focos. 2007.

SANTOS, Paulo Pereira dos. Evolução econômica do Rio Grande do Norte (séc. XVI ao XXI):

500 anos da história econômica do Rio Grande do Norte. $2^{\text {a }}$ ed. Natal: Departamento da Imprensa do Estado, 2001.

SILVA, Anieres Barbosa da. GOMES, Rita de Cássia da Conceição. SILVA, Valdenido Pedro da (org.). Pequenas cidades: uma abordagem geográfica. EDUFRN. Natal-RN, 2009. 